\title{
Effect of level of dietary soy oil supplementation and concentrate to forage ratio on feed intake, methane production and rumen fermentation variables of beef steers
}

\section{K J Petrie ${ }^{1}$, T M Boland ${ }^{1}$, K J Hart ${ }^{1}$, C M McCarney ${ }^{1}$, S M Waters ${ }^{2}$, D A Kenny ${ }^{2}$}

${ }^{1}$ University College Dublin, Dublin, Ireland, ${ }^{2}$ Teagasc Bioscience Research Centre, Grange, Meath, Ireland

Email: kirstie.petrie@ucd.ie

Introduction Agriculture currently accounts for $12 \%$ of total global green house gas (GHG) emissions with enteric fermentation being the largest biogenic source of agricultural methane $\left(\mathrm{CH}_{4}\right)$ and accounting for almost $13 \%$ of total Irish GHG emissions (McGettigan et al., 2008). Ruminal methanogenesis represents a loss to the animal of up to $8.5 \%$ of gross energy intake (GEI) (Tamminga et al., 2007) therefore a reduction in enteric $\mathrm{CH}_{4}$ production should reduce this inefficiency as well as the environmental impact of ruminant production. Soy oil (SO) is a natural source of unsaturated long chain fatty acids and it has been shown previously that dietary SO supplementation can substantially reduce ruminal methanogenesis of beef cattle on a high concentrate diet (Jordan et al. 2006). However little is known on how this effect is mediated or whether it is consistent across lower concentrate to forage ratio (C:F) diets. The aim of this study, therefore, was to investigate the effect of dietary $\mathrm{SO}$ inclusion and $\mathrm{C}: \mathrm{F}$ ratio on feed intake, $\mathrm{CH}_{4}$ emissions, rumen fermentation variables and rumen microbial measurements in beef cattle.

Materials and methods Eight mature Limousin X steers with a mean body weight (BW) $( \pm$ S.E.) of $521( \pm 11.7) \mathrm{kg}$ and 4 ruminally cannulated Limousin X steers with a mean BW ( \pm S.E.) of $484( \pm 26.4) \mathrm{kg}$ were allocated at random to a $2 \times 2$ factorial, latin square design with four, $28 \mathrm{~d}$ periods. Animals were allocated within period to one of two levels of dietary $\mathrm{C}:$ F ratio (50:50 v 90:10; barley straw as the forage source) and one of two levels of dietary SO inclusion $(0 \mathrm{v} 60 \mathrm{~g} / \mathrm{kg}$ dry matter (DM)). Diets were offered at $95 \%$ of voluntary DMI and formulated to be isonitrogenous (140 g/kg DM). Feed intake was measured daily, with $\mathrm{CH}_{4}$ determined using the sulphur hexafluoride tracer $\left(\mathrm{SF}_{6}\right)$ gas technique on $\mathrm{d} 21-25$ of each period on the 8 non-cannulated steers. Rumen fluid was sampled from the ruminally cannulated steers on $\mathrm{d} 27$ and 28 for analysis of ruminal VFA, ammonia and microbial profile. The mcrA gene and 16S rRNA gene were quantified using specific genomic primers and real-time quantitative polymerase chain reaction (PCR) for both liquid and solid phases of rumen digesta. Data were analysed using the MIXED procedure (PROC MIXED) of SAS.

Results The effect of C:F ratio and $\mathrm{SO}$ supplementation on $\mathrm{CH}_{4}$ emissions is presented in Figure 1. There were no oil $\mathrm{x}$ C:F interactions detected $(\mathrm{P}>0.05)$. Inclusion of SO reduced $(P<0.001)$ daily $\mathrm{CH}_{4}$ by $51 \%$, intake corrected $\mathrm{CH}_{4}$ by $45 \%$ and GE intake corrected $\mathrm{CH}_{4}$ by $51 \%$. At the higher $\mathrm{C}: \mathrm{F}$ ratio, dry matter intake (DMI) corrected $\mathrm{CH}_{4}$ was reduced $(P=0.006)$ by $27 \%, \mathrm{CH}_{4}$ corrected for GE intake was reduced $(P=0.003)$ by $32 \%$ and there was also a trend $(P=0.07)$ towards decreased overall daily $\mathrm{CH}_{4}$. Dry matter intake was greatest $(\mathrm{P}<0.001)$ at the higher $\mathrm{C}: \mathrm{F}$ ratio but was reduced by $7.5 \%$ following SO inclusion $(P=0.02)$. Apparent whole-tract digestibilities of DM $(P=0.04), \mathrm{OM}(P=0.03)$ and GE $(P=$ $0.008)$ were reduced after SO inclusion, with the higher $\mathrm{C}: \mathrm{F}$ ratio increasing DM $(P=0.02), \mathrm{OM}(P=0.03)$ and GE $(P=$ $0.04)$ digestibility. Treatment had no effect on total ruminal concentrations of VFA. However, acetate to propionate ratio was decreased $(P<0.001)$ by the higher $\mathrm{C}: \mathrm{F}$ ratio and by SO inclusion. Ammonia was lower at both the higher $\mathrm{C}: \mathrm{F}$ ratio $(P$ $<0.001)$ and following SO inclusion $(P=0.002)$. There was a tendency towards a reduction $(P=0.0539)$ in the relative abundance of the mcrA gene in digesta of animals fed SO in the ruminal liquid phase.

Conclusion This study demonstrated that the addition of SO, at $60 \mathrm{~g} / \mathrm{kg} \mathrm{DM}$, to the diet of beef steers dramatically reduces daily and GEI adjusted $\mathrm{CH}_{4}$ by over $50 \%$ and DMI corrected $\mathrm{CH}_{4}$ by $45 \%$. Increased C:F ratio also reduced $\mathrm{CH}_{4}$ when corrected for DMI and GEI (by 26 and 32\% respectively) and it tended to reduce daily $\mathrm{CH}_{4}$ emissions whilst increasing DMI. This suggests that if both strategies were utilised with finishing cattle the potential exists to significantly reduce the total lifetime emissions from beef cattle.

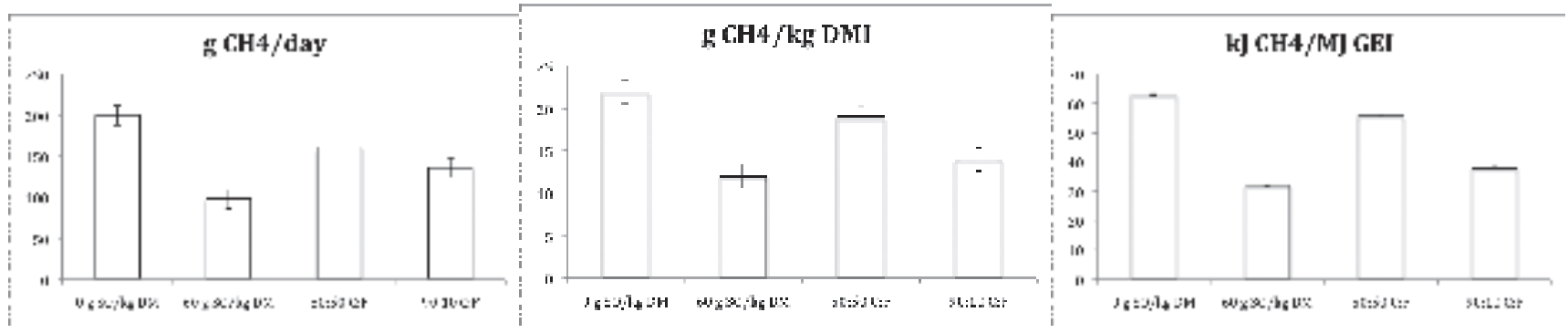

Figure 1 Effect of dietary $\mathrm{SO}$ supplementation and $\mathrm{C}: \mathrm{F}$ ratio on daily ruminal $\mathrm{CH}_{4}$ emissions expressed on a daily, per $\mathrm{kg}$ of DMI and per MJ GEI basis

Acknowledgements Funding for this research was provided under the Irish National Development Plan, through the Research Stimulus Fund, administered by the Department of Agriculture, Fisheries \& Food

\section{References}

Jordan, E., D. Kenny, M. Hawkins, R. Malone, D. K. Lovett, and F. P. O' Mara. 2006. Journal of Animal Science 84, 24182425 .

McGettigan, M. P., P. Duffy, P. Hyde, and P. O'Brien. 2008, Johnstown Castle Estate, Wexford, Ireland.

Tamminga, S., A. Bannik, J. Dijkstra, and D. Zom. 2007. Wageningen University. 